EGU2020-4032, updated on 21 Apr 2020

https://doi.org/10.5194/egusphere-egu2020-4032

EGU General Assembly 2020

(c) Author(s) 2020. This work is distributed under

the Creative Commons Attribution 4.0 License.

\title{
Discrete changes in fault free-face roughness: constraining past earthquakes characteristics
}

Olaf Zielke ${ }^{1}$, Lucilla Benedetti ${ }^{2}$, P. Martin Mai ${ }^{1}$, Magali Rizza², Jules Fleury², Lea Pousse Beltran², Irene Puliti ${ }^{3}$, and Bruno Pace ${ }^{3}$

${ }^{1}$ ErSE, King Abdullah University of Science and Technology, Thuwal, Saudi Arabia (olaf.zielke@kaust.edu.sa)

${ }^{2}$ CEREGE CNRS-IRD, Aix-Marseille Université, Aix en Provence, France

${ }^{3}$ GEOFISICA DELLA TERRA SOLIDA, Università degli Studi G. d'Annunzio Chieti e Pescara, Chieti, Italy

A driving motivator in many active tectonics studies is to learn more about the recurrence large and potentially destructive earthquakes, providing the means to assess the respective fault's future seismic behavior. Doing so requires long records of earthquake recurrence. The lack of sufficiently long instrumental seismic records (that would be best suited for this task) has led to the development of other approaches that may constrain the recurrence of surface rupturing earthquakes along individual faults. These approaches take different forms, depending on the specific tectonic and geographic conditions of an investigated region.

For example, around the Mediterranean Sea, we frequently find bedrock scarps along normal faults. Assuming that bedrock (i.e., fault free-face) exposure is caused by the occurrence of subsequent large earthquakes, we may measure certain rock properties to constrain the time and size of past earthquakes as well as the fault's geologic slip-rate. A now-classic example in this regard is the measurement of ${ }^{36} \mathrm{Cl}$ concentrations along exposed fault scarps in limestones.

For the presented study, we looked at another property of the exposed fault free-face, namely its morphologic roughness. We aim to identify whether fault free-face roughness contains information to constrain earthquake occurrence and fault slip-rates following the assumption that sub-sequent exposure to the elements and sub-areal erosional conditions may leave a signal in how rough (or smooth) the fault free-face is (assuming a somewhat uniform pre-exposure roughness). Here, we present observations of fault free-face surface roughness for the Mt. Vettore fault (last ruptured in 2016) and the Rocca Preturo fault (The underlying models of fault free-face morphology were generated using the Structure-from-Motion approach and a large suite of unregistered optical images.). Employing different metrics to quantify morphologic roughness, we were indeed able to observe a) an increase in surface roughness with fault scarp height (i.e., longer exposure to sub-areal erosion causes higher roughness), and b) distinct (rather than gradual) changes in surface roughness, suggesting a correlation to individual exposure events such as earthquakes. Hence, fault free-face morphology of bedrock faults may serve as an additional metric to reconstruct earthquake recurrence patterns. 